\title{
Psychometric Properties of the Turkish Version of the Satisfaction with Amplification in Daily Living Questionnaire in Hearing Aid Users
}

DOI: $10.3766 /$ jaaa.17073

\author{
Meltem Genç* \\ Bünyamin Çildir $\dagger$ \\ Mesut Kaya $\ddagger$
}

\begin{abstract}
Background: Assessing hearing aid satisfaction is important for hearing aid adaptation in individuals who have hearing loss. Each user should be compared to oneself during the adaptation of the hearing aid and the determination of the satisfaction level, because, each user has their own demands and expectations. Therefore, the survey evaluations which reveal the personal preferences and expectations gain importance in the determination of the benefit and satisfaction rate for hearing aid users.
\end{abstract}

Purpose: The purpose of this study was to evaluate the reliability of the Turkish version of the Satisfaction with Amplification in Daily Living (TSADL) among hearing aid users.

Research Design: The original Satisfaction with Amplification in Daily Living (SADL) questionnaire was translated from English to the TSADL. Linguistic adaptation attempted to ensure equivalency, both grammatically and idiomatically, and was assessed by investigators related to the field.

Study Sample: One hundred and sixty hearing aid users with sensorineural hearing loss, aged 18 to $90 \mathrm{yr}(54.51 \pm 18.21)$, who had been using a hearing aid regularly for more than 6 mo participated in the study; seventy three (45.10\%) were male and $87(54.30 \%)$ were female.

Data Collection: Participants completed the TSADL twice, 3 mo apart (long enough to forget their replies in the first application but short enough to prevent any changes to the measured properties).

\begin{abstract}
Results: When factor analysis of the questionnaire was performed, subdimension factor loadings were found to range from 0.744 to 0.854 for "Positive Effect," 0.62 to 0.985 for "Personal Image," and 0.903 to 0.913 for "Adverse Features"; the factor loading of "Service and Cost" was 0.983 . Because all factor loadings were above 0.30 , no items were excluded from the Turkish version of the questionnaire. Although the TSADL retained the original four factors, because of differences in Turkish social structures and perspectives, questions \#12 and \#15 revealed an association between the "Service and Cost" and "Positive Effects" subdimensions.
\end{abstract}

Conclusions: The SADL-TR scale can be reliably used in clinical studies to rapidly assess patient satisfaction, compare satisfaction levels, determine normative satisfaction level, compare various amplifications, and gather administrative outcome data.

Key Words: hearing aids, personal satisfaction, SADL

Abbreviations: CFA = confirmatory factor analysis; SADL = Satisfaction with Amplification in Daily Living questionnaire; SD = standard deviation; TSADL = Turkish version of the Satisfaction with Amplification in Daily Living questionnaire; WDS = word discrimination score

*Gatases Hearing Center, Ankara, Turkey; †Department of Audiology, Hacettepe University, Ankara, Turkey; $\ddagger$ llgi Eye and Ear Institute, Ankara, Turkey

Corresponding author: Bünyamin ÇILDIR, Department of Audiology, Hacettepe University, 06100 Sihhiye, Ankara, Turkey; Email: bunyamin. cildir@hacettepe.edu.tr 


\section{INTRODUCTION}

$\mathrm{A}$ ccording to a report issued by the World Health Organization in 2015, life-complicating hearing loss occurs in 360 million individuals across the world, and prevalence increases with age. Moreover, the same report states that, in addition to elderly people, hearing loss affects 32 million children under the age of $15 \mathrm{yr}$. When satisfaction levels were taken into consideration, the rate of individuals encountering difficulty in comprehension, despite use of a hearing aid, increased with age (Yearbook, 2004).

In the "Assessment of the Satisfaction levels in Hearing Aid Users" study, Hamurcu et al found that hearing problems led to a poor quality of life, depressive symptoms, and reduced functional capacity (Hamurcu et al, 2012, consistent with previous work by Lupsakko et al, 2005). Individuals encountering hearing problems may also have serious social issues.

Hearing aids seem to be the only option for correcting hearing loss in cases that cannot be improved with drugs or surgery (Hamurcu et al, 2012).

Assessment of hearing aid suitability is difficult, even in developed countries, because of the lack of sufficient audiology experts or shared evaluation methods, particularly among patients with a low socioeconomic statuses (Arslan and Genovese, 1996; Kırkım et al, 2008; Kumar, 2001).

Three motivational processes should be considered in the hearing aid use of individuals encountering hearing problems, including acceptance, benefit, and satisfaction. Satisfaction does not occur without acceptance, and acceptance and benefit do not guarantee device satisfaction. Whereas benefit can be determined by target-driven tests, satisfaction depends entirely on personal judgment following extended hearing aid use (Hosford-Dunn, 2000).

Patients either accept or deny hearing aid use. By determining and quantifying the variables that underlie patients' acceptance of hearing aids, both during and before use, we can potentially predict which patients will embrace or resist hearing aid use. The primary goal is benefit maximization during adaptation. Thus, failing to select the device in accordance with the patient's situation may impede preliminary acceptance (Cox and Alexander, 2000).

Similar satisfaction studies conducted in other countries have revealed factors, such as early detection of hearing loss, early acceptance by the patient, and prompt commencement of use after diagnosis, that influence satisfaction with hearing aids (Matthews et al, 1990).

Adaptation of hearing aids and determination of satisfaction should be individualized to the user, in accordance with their demands and expectations. It is not always possible to satisfy two users, with similar audiological findings, with the same device and adaptation. For instance, whereas listening to a news reporter is important for some people, listening to an orchestra is more important to others. Thus, the primary goal, in terms of amplification in hearing aids, should be to attain maximum benefit, and clinicians should explore individual functional gains.

According to the Health Practice Declaration in the current system in Turkey, benefit is evaluated by an increase in Word Discrimination Score (WDS). In many studies, a positive correlation was found between the experience of using hearing aids and the WDS (Stephens, 2002; Bille and Parving, 2003), supporting this approach. However, although an increase in the WDS score is an indicator of benefit, given the lack of testing settings for replicating the environments encountered by hearing aid users during their various daily activities, it is insufficient for determining maximum benefit. Therefore, questionnaires, which reveal personal preferences and expectations, are import for determining and quantifying benefit and satisfaction in hearing aid users.

Audiological assessment, rational decision-making (as to which hearing aid device should be implemented), and expected duration of use, should also be evaluated. Nevertheless, even when all factors are provided, adaptation of the hearing aid to the patient and implementation of the correct ear-mold are of utmost importance. Therefore, while adapting the hearing aid, assessment of hearing aid gain by real ear measurement and periodical control of accessories, such as the mold and battery, are required. By these means, it is possible to enhance patient satisfaction. There are several questionnaires, developed by audiologists, to assess the effectiveness of hearing aids and satisfaction among patients (Gatehouse, 1994; Cox and Alexander, 2002). Individual reports are important tools to indicate the effects of disability and handicap in daily life. Individual reports can also be used in treatment planning and during follow-up to assess improvement. The most commonly used questionnaires were developed to assess improvements in communication and reductions in disability and handicap (Barcham and Stephens, 1980). Subjective assessment of hearing aid fitting can be performed using patient questionnaires, such as the Satisfaction with Amplification in Daily Life (SADL), International Outcome Inventory for Hearing Aids, Hearing Handicap Inventory for Adults, Abbreviated Profile of Hearing Aid Benefit, or Hearing Inventory for Elderly questionnaires. Cox and Alexander demonstrated the benefits of patient questionnaires for providing important information for determining patient needs via the subjective individual assessment of disability effects in daily life. The information obtained from the reports are helpful for planning and applying treatment strategies (NAL NL1 or NAL NL2) (Cox and Alexander, 2000). The feedback obtained from hearing aid satisfaction questionnaires 
are used to assess device fitting and standardize the service. Among other questionnaires, the SADL questionnaires is widely used to assess every aspect of hearing aid use (Hosford-Dunn, 2000; Hosford-Dunn and Halpern, 2001).
Hosford-Dunn and Halpern (2001) identified variables which had small effects on SADL results, including daily hours of hearing aid use, previous years of hearing aid experience, self-perceived hearing difficulties, hearing aid style and cost, and type of processing used in the device.

GONLOKK HAYATTA AMPLIFIKASYON (SESI ARTIRMA) MEMNUNIYETI

\begin{tabular}{|c|c|}
\hline \multicolumn{2}{|c|}{ 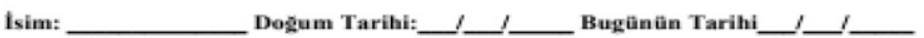 } \\
\hline 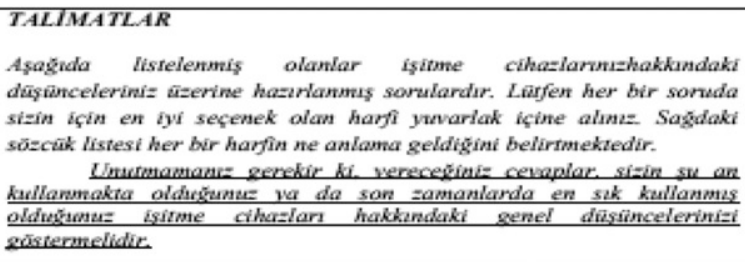 & $\begin{array}{l}\text { A) Asla } \\
\text { B) Biraz } \\
\text { C) Kismen } \\
\text { D) Orta } \\
\text { E) Oldukça } \\
\text { F) Cok }\end{array}$ \\
\hline $\begin{array}{l}\text { 1. Ișitme cihazı kullanmadığınz zamanlara kıyasla, ișitme } \\
\text { cihazlarınız en sık konuştugunuz insanları anlamanıza yardımeı } \\
\text { oluyor mu? }\end{array}$ & A B CDEFG \\
\hline $\begin{array}{l}\text { 2.Ișitme cihazınız duymak istediginiz sesler dısandaki sesleri } \\
\text { aldigında (duymak istediginiz sesleri engelleyen) rahatsaz oluyor } \\
\text { musunuz? }\end{array}$ & A B C DEFG \\
\hline $\begin{array}{l}\text { 3. Işitme cihazı almanın sizin yararınıza olduğunu dușūnūyoe } \\
\text { musunuz? }\end{array}$ & A B CDEFG \\
\hline $\begin{array}{l}\text { 4. Sizce insanlar, işitme cihazınızı taktıgınızdaişitme kaybınızı } \\
\text { farkına daha cok mu varıyorlar? }\end{array}$ & A B CDEFG \\
\hline $\begin{array}{l}\text { 5. Isitme cihazınız insanlardan soylediklerini tekrar etmelerini } \\
\text { isteginiz zamanların sayısım azaltt mı? }\end{array}$ & A B CDEFG \\
\hline 6. Sizce işitme cihazınz cektiginiz zahmete degiyor mu? & ABCDEFG \\
\hline $\begin{array}{l}\text { 7. Isitme cihazınızdan geri bildirim (otme sesi) olmadan yeterli } \\
\text { ses șiddetini alamamanız sizi rahatsı ediyor mu? }\end{array}$ & A BCDEFG \\
\hline 8. Ișitme cihazınızin gōrünüșinden ne kadar memnunsunuz? & A BCDEFG \\
\hline 9. Ișitme cihazını takmanız Jzgüveninizi artırryor mu? & ABCDEFG \\
\hline 10. Ișitme cihazanızdan duydugunuz ses ne kadar dogal? & ABCDEFG \\
\hline 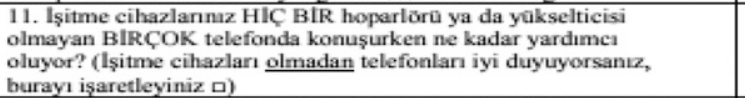 & A B CDEFG \\
\hline 12. Size ișitme cihazmuzı veren kiși ne dereoe yetkili bir kişydi? & ABCDEFG \\
\hline $\begin{array}{l}\text { 13. Sizce işitme cihazınız takmak sizi daha az yetenekli mi } \\
\text { gôsteriyor? }\end{array}$ & A B CDEFG \\
\hline 14. Issitme cihazlannan maliyeti size makul geliyor mu? & A BCDEFG \\
\hline $\begin{array}{l}\text { 15. Işitme cihazlannazin guvenilirliginden ne kadar } \\
\text { memnunsunuz? }\end{array}$ & A BCDEFG \\
\hline
\end{tabular}

Lütfen ilave maddelere cevap veriniz

\begin{tabular}{|c|c|c|c|}
\hline 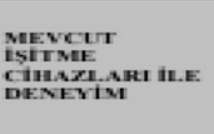 & 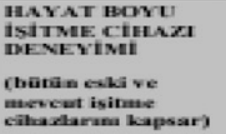 & 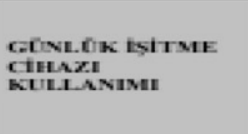 & 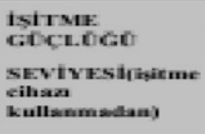 \\
\hline 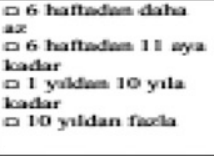 & 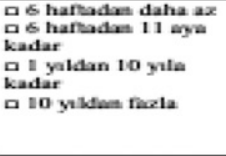 & 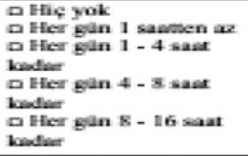 & 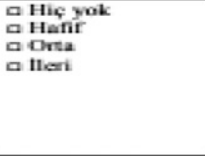 \\
\hline
\end{tabular}

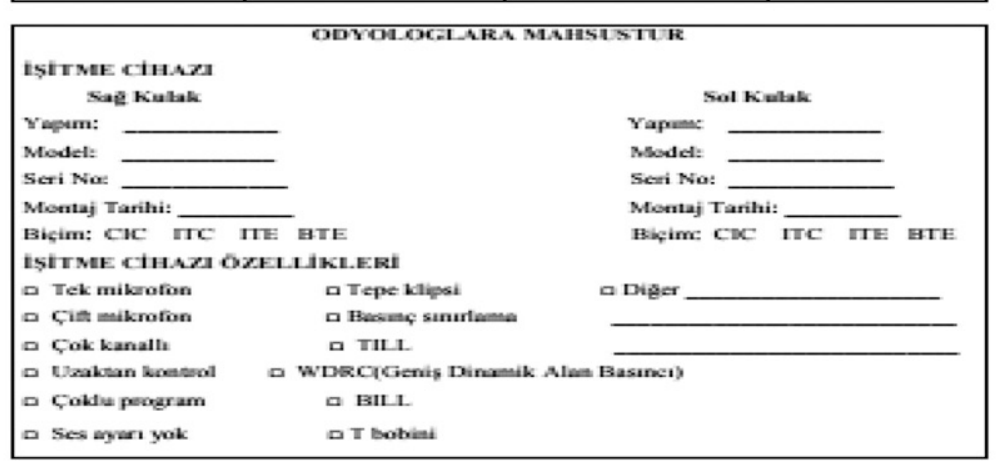

Memfis Öniversitesi, 1999

Figure 1. Turkish version of the Satisfaction with Amplification in Daily Living. 
Pe1: Compared to using no hearing aid at all, do your hearing aids help you understand the people you speak with most frequently? Nf2: Are you frustrated when your hearing aids pick up sounds that keep you from hearing what you want to hear?

Pe2: Are you convinced that obtaining your hearing aids was in your best interests?

Pi1: Do you think people notice your hearing loss more when you wear your hearing aids?

Pe3: Do your hearing aids reduce the number of times you have to ask people to repeat?

Pe4: Do you think your hearing aids are worth the trouble?

Nf2: Are you bothered by an inability to get enough loudness from your hearing aids without feedback (whistling)?

Pi2: How content are you with the appearance of your hearing aids?

Pe5: Does wearing your hearing aids improve your self confidence?

Pe6: How natural is the sound from your hearing aids?

Nf3: How helpful are your hearing aids on MOST telephones with NO amplifier or loudspeaker?

Sc1: How competent was the person who provided you with your hearing aids?

Pi3: Do you think wearing your hearing aids makes you seem less capable?

Sc2: Does the cost of your hearing aids seem reasonable to you?

Sc3: How pleased are you with the dependability (how often they need repairs) of your hearing aids?

$\overline{\mathrm{NF}}=$ negative feature; PE = positive effect; PI = personal image; SC = service and cost.

Moreover, awareness of nonaudiological variables, such as individual age, gender, personality type, social support, attitude toward hearing aid use, socioeconomic level, and general health status, which can potentially affect user device-related satisfaction, is important (Uriarte et al, 2005).

Whereas from the clinicians' viewpoints, the triple variables (acceptance, benefit, and satisfaction) provide important data to assist with hearing for many years, outcome evaluation of present application focuses on benefits only (Cox and Alexander, 2000).

When developing the SADL scale, to yield a method capable of identifying and measuring the various constituents and levels of satisfaction, Cox and Alexander considered several additional terms alongside 25 trial items. They also placed importance on the development of a scale with an appropriate length for clinical use (Cox and Alexander, 2000).

During the preparation of the SADL scale, patients were requested to specify only one global satisfaction value (Cox and Alexander, 2000). However, using a single global value remains limited in patient evaluation. For instance, in terms of global satisfaction, two patients might give a score of 3 (between one and seven), indicative of dissatisfaction with their hearing aids. However, this information does not explain why the patients are dissatisfied, or whether they are dissatisfied for the same reason. Hence, factors that can be used to determine problematic personal fields are required and, thus, singlequestion evaluation of satisfaction did not take place in the questionnaire (Cox and Alexander, 2000). In the Turkish scale, additional items were not used.

The SADL questionnaire consists of 15 items and four subscales. Both individual subscale scores and an overall (global) score may be calculated, the global score is obtained by averaging the scores of all 15 items and subscale scores are obtained by averaging the scores of relevant subscale items.

Briefly, the subscales are as follows:
- Positive Effect-advanced functions in psychoacoustic and psychological fields

- Service and Cost-the competence of the distributor and the cost of the hearing aid

- Adverse Features-the potential effects of adverse situations encountered while using the hearing aid

- Personal Image - the image of the person using the hearing aid, from the perspective of the user and others

All items are scored on a seven-point scale, with the highest score indicating maximum satisfaction. Therefore, the global and subscale score range from 1 to 7 . The Cronbach's alpha coefficient value for the SADL global score is 0.82 (Cox and Alexander, 2000).

Table 2. The Descriptive Statistics of the Survey Questions

\begin{tabular}{lcccc}
\hline & \multicolumn{4}{c}{ Start } \\
\cline { 2 - 5 } $\mathrm{N}=160$ & Minimum & Maximum & Median & Mean \pm SD \\
\hline Pe1 & 1.0 & 7.0 & 6.0 & $5.80 \pm 1.21$ \\
Nf1 & 2.0 & 7.0 & 7.0 & $6.50 \pm 1.04$ \\
Pe2 & 3.0 & 7.0 & 6.0 & $6.07 \pm 1.07$ \\
Pi1 & 1.0 & 7.0 & 5.0 & $4.77 \pm 1.55$ \\
Pe3 & 2.0 & 7.0 & 6.0 & $5.52 \pm 1.08$ \\
Pe4 & 1.0 & 7.0 & 6.0 & $5.86 \pm 1.21$ \\
Nf2 & 1.0 & 7.0 & 6.0 & $5.75 \pm 1.24$ \\
Pi2 & 2.0 & 7.0 & 6.0 & $5.66 \pm 1.41$ \\
Pe5 & 1.0 & 7.0 & 6.0 & $5.65 \pm 1.25$ \\
Pe6 & 2.0 & 7.0 & 6.0 & $5.71 \pm 0.99$ \\
Nf3 & 3.0 & 7.0 & 7.0 & $6.55 \pm 0.83$ \\
Sc1 & 2.0 & 7.0 & 7.0 & $6.48 \pm 0.89$ \\
Pi3 & 3.0 & 7.0 & 7.0 & $6.26 \pm 1.08$ \\
Sc2 & 1.0 & 7.0 & 2.0 & $2.53 \pm 1.02$ \\
Sc3 & 2.0 & 7.0 & 7.0 & $6.39 \pm 0.93$ \\
\hline NF $=$ negative feature; PE $=$ positive effect; PI = personal image; &
\end{tabular}


Table 3. The Factor Structure of the SADL Scale

\begin{tabular}{|c|c|c|c|c|}
\hline $\begin{array}{l}\text { Scale } \\
\text { Subdimensions }\end{array}$ & Items & $\begin{array}{l}\text { Factor } \\
\text { Loadings of } \\
\text { the Items }\end{array}$ & $\begin{array}{c}\text { Eigenvalues } \\
\text { of the } \\
\text { Factors }\end{array}$ & $\begin{array}{c}\text { Variances } \\
\text { Explained by } \\
\text { the Factors }\end{array}$ \\
\hline Positive effect & $\begin{array}{l}\text { Pe1 } \\
\text { Pe2 } \\
\text { Pe3 } \\
\text { Pe4 } \\
\text { Pe5 } \\
\text { Pe6 } \\
\text { Nf3 } \\
\text { Sc1 } \\
\text { Sc3 }\end{array}$ & $\begin{array}{l}0.773 \\
0.820 \\
0.744 \\
0.854 \\
0.796 \\
0.766 \\
0.765 \\
0.771 \\
0.801\end{array}$ & 5.91 & 39.37 \\
\hline $\begin{array}{l}\text { Personal } \\
\text { image and } \\
\text { appearance }\end{array}$ & $\begin{array}{l}\mathrm{Pi1} \\
\mathrm{Pi} 2 \\
\mathrm{Pi3}\end{array}$ & $\begin{array}{l}0.973 \\
0.985 \\
0.962\end{array}$ & 3.27 & 21.81 \\
\hline Adverse features & $\begin{array}{l}\text { Nf1 } \\
\text { Nf2 }\end{array}$ & $\begin{array}{l}0.913 \\
0.903\end{array}$ & 1.64 & 10.92 \\
\hline Cost & Sc3 & 0.983 & 1.03 & 6.89 \\
\hline
\end{tabular}

$\overline{\mathrm{NF}}=$ negative feature; $\mathrm{PE}=$ positive effect; $\mathrm{PI}=$ personal image; $\mathrm{SC}=$ service and cost.

Kaiser-Meyer-Olkin Measure of Sampling Adequacy $(\mathrm{KMO})=0.821$.

Extraction Method: Principal Component Analysis.

Rotation Method: Quartimax with Kaiser Normalization.

The aim of this study was to translate the SADL questionnaire into Turkish and evaluate the reliability of the Turkish SADL, the questionnaire for assessing satisfaction in daily living among hearing aid user.

\section{MATERIALS AND METHODS}

$\mathrm{T}$ he study was conducted in the Turgut Özal University Medical Faculty Audiology and Speech Disorders Clinic. Approval was obtained from the Turgut Özal University for Non-Pharmaceutical Clinical Studies Ethics Committee on September 26, 2014. Patients diagnosed with sensorineural hearing loss and using hearing aids regularly for at least 3 mo were included in the study. One hundred and sixty hearing aid users, aged 18 to $90 \mathrm{yr}$ were included in the study. Audiometric assessment was performed in all patients, after ear nose and throat physical examination, using pure sounds at frequencies of 500,1000 , and $2000 \mathrm{~Hz}$, as per threshold levels for discriminating speech from the environment. Patients with bilateral symmetrical sensorineural hearing loss at various levels (minor, moderate, and severe), postlingual hearing loss (native Turkish speaking), and without any mental, neurological, and psychological disorders were included in the study.

\section{Translation and Cultural Adaptation of the Questionnaire}

The questionnaire was translated from English to Turkish by two translators; linguistic adaptation aimed to ensure equivalency both grammatically and idiomatically,

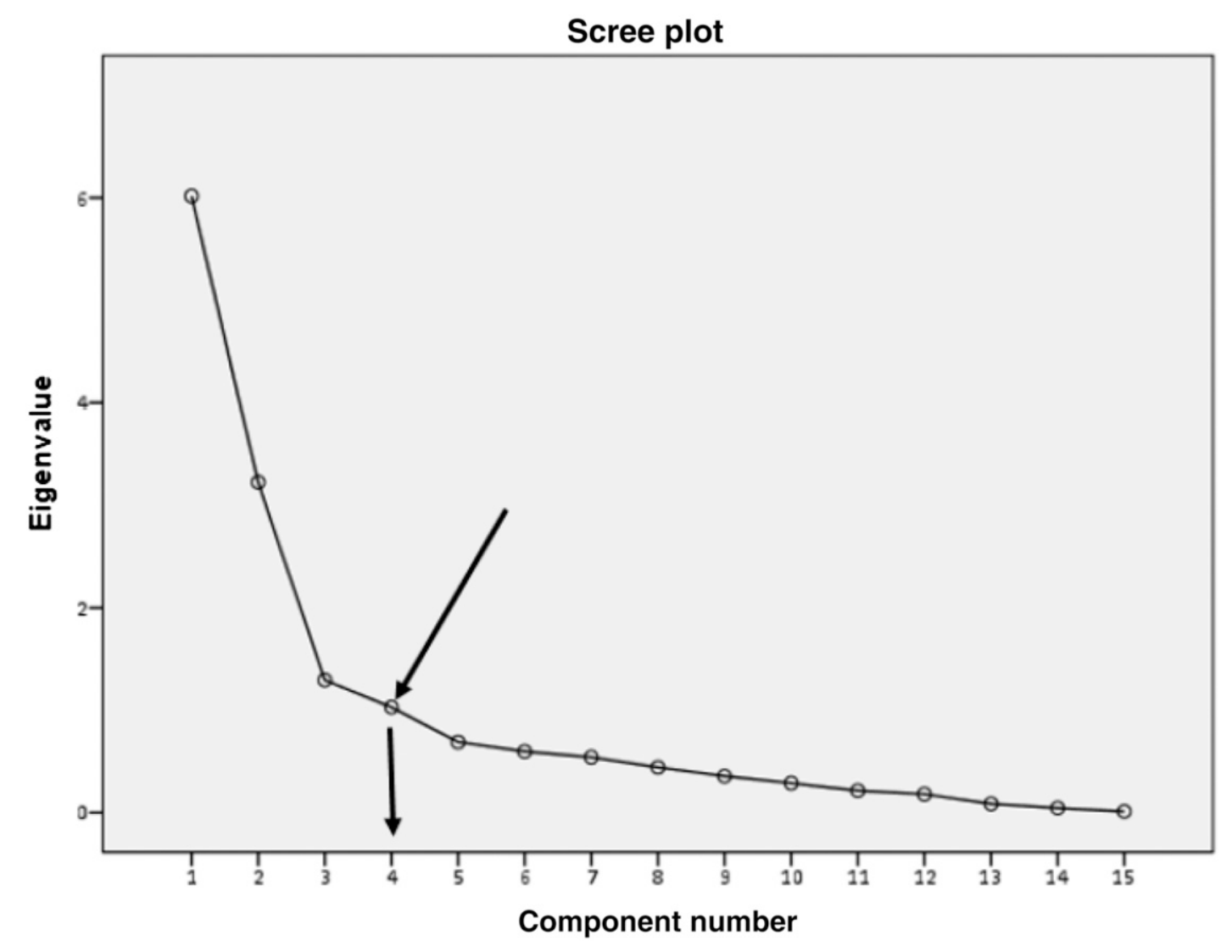

Figure 2. The scree plot graph. 
and assessments of the investigators in the field were measured. The translated questions were initially applied to a group of ten patients; the second question was subsequently rewritten without altering the content integrity, and the final Turkish version (Figure 1) was translated into English via a systematic forward backward translation process. The final English version (Table 1) was checked by a native speaker, and comparison between the original and final English versions was made.

\section{Translation of the SADL Questionnaire}

To determine the correctness of the participants' device amplifications, their hearing loss and real ear measurement values were evaluated. In addition, issues such as tearing and obstruction in hearing aid ear molds were considered. The study was completed by 160 individuals; $73(45.1 \%)$ were male and $87(54.3 \%)$ were female. The questionnaire was completed by each participant twice, 3 mo apart (long enough for participants to forget their replies at the first application, but short enough to prevent any changes to the measured properties).

\section{Statistical Analysis}

The statistical software packages SPSS 23.0 and AMOS 23.0 (IBM Corporation, Armonk, NY) were used for data analysis. Assessment of compliance between the original English and translated Turkish scale structures was carried out with validity and reliability analyses, internal consistency (Cronbach's alpha), item analysis, and test/retest approaches were used for reliability analyses, and criterion ( $t$-test, analysis of variance, etc.) and structural validity [explanatory factor analysis and confirmatory factor analysis (CFA)] were included in the analyses of validity. Original SADL questionnaire were in Table 1.

Quantitative data are expressed as mean \pm standard deviation (SD) and median range (minimum-maximum). Categorical data are expressed as number (n) and percentage (\%). Data were analyzed at the $95 \%$ confidence level, and $p$-values less than 0.05 were considered statistically significant.

\section{RESULTS}

Q uestionnaire response details are shown in Table 2 .

\section{Structural-Xonceptual Validity of the Turkish Satisfaction with Amplification in Daily Living (TSADL) Questionnaire}

\section{Factor Analysis}

Structural validity of the SADL questionnaire was assessed by performing factor analysis. The factor loadings, eigenvalues, and the explained variances are shown in Table 3.

When the result of the Bartlett's sphericity test was analyzed, the obtained $\chi^{2}$ value was found to be statistically significant $\left(X^{2}=2,496.083 ; p<0.001\right)$. The items were found to gather in four subdimensions. The subdimensions for "Positive Effect," "Personal Image and Appearance," "Adverse Features," and "Service and Cost" explained $39.37 \%, 21.81 \%, 10.92 \%$, and $6.89 \%$ of the variance, respectively; in total, these four subdimensions explained $78.99 \%$ of the total variance. Two-thirds

\section{Table 4. The Correlations between Items}

\begin{tabular}{|c|c|c|c|}
\hline \multirow{2}{*}{$\begin{array}{l}\text { Factors } \\
\text { Positive effect }\end{array}$} & \multicolumn{2}{|c|}{ Items } & \multirow{2}{*}{$\frac{R}{0.620}$} \\
\hline & Pe1 & $\mathrm{Pe} 2$ & \\
\hline & $\mathrm{Pe} 1$ & $\mathrm{Pe} 3$ & 0.568 \\
\hline & Pe1 & Pe4 & 0.632 \\
\hline & $\mathrm{Pe} 1$ & Pe5 & 0.741 \\
\hline & Pe1 & Pe6 & 0.578 \\
\hline & Pe1 & NF3 & 0.569 \\
\hline & Pe1 & Sc1 & 0.654 \\
\hline & Pe1 & $\mathrm{Sc} 3$ & 0.545 \\
\hline & $\mathrm{Pe} 2$ & $\mathrm{Pe} 3$ & 0.754 \\
\hline & $\mathrm{Pe} 2$ & Pe4 & 0.699 \\
\hline & $\mathrm{Pe} 2$ & Pe5 & 0.688 \\
\hline & $\mathrm{Pe} 2$ & Pe6 & 0.874 \\
\hline & $\mathrm{Pe} 2$ & NF3 & 0.506 \\
\hline & $\mathrm{Pe} 2$ & Sc1 & 0.543 \\
\hline & $\mathrm{Pe} 2$ & Sc3 & 0.569 \\
\hline & $\mathrm{Pe} 3$ & Pe4 & 0.630 \\
\hline & $\mathrm{Pe} 3$ & Pe5 & 0.689 \\
\hline & $\mathrm{Pe} 3$ & Pe6 & 0.785 \\
\hline & $\mathrm{Pe} 3$ & NF3 & 0.785 \\
\hline & $\mathrm{Pe} 3$ & Sc1 & 0.525 \\
\hline & $\mathrm{Pe} 3$ & $\mathrm{Sc} 3$ & 0.544 \\
\hline & Pe4 & Pe5 & 0.624 \\
\hline & Pe4 & Pe6 & 0.584 \\
\hline & $\mathrm{Pe} 4$ & NF3 & 0.604 \\
\hline & $\mathrm{Pe} 4$ & Sc1 & 0.590 \\
\hline & $\mathrm{Pe} 4$ & Sc3 & 0.613 \\
\hline & Pe5 & Pe6 & 0.597 \\
\hline & Pe5 & NF3 & 0.552 \\
\hline & Pe5 & Sc1 & 0.522 \\
\hline & Pe5 & $\mathrm{Sc} 3$ & 0.567 \\
\hline & Pe6 & NF3 & 0.932 \\
\hline & Pe6 & Sc1 & 0.575 \\
\hline & Pe6 & $\mathrm{Sc} 3$ & 0.567 \\
\hline & Nf3 & Sc1 & 0.577 \\
\hline & Nf3 & Sc3 & 0.569 \\
\hline & Sc1 & $\mathrm{Sc} 3$ & 0.890 \\
\hline \multirow[t]{3}{*}{ Personal image and appearance } & Pi1 & $\mathrm{Pi} 2$ & 0.981 \\
\hline & Pi1 & $\mathrm{Pi} 3$ & 0.923 \\
\hline & $\mathrm{Pi} 2$ & Pi3 & 0.958 \\
\hline \multirow[t]{2}{*}{ Adverse features } & $\mathrm{Pi} 2$ & Pi3 & 0.958 \\
\hline & Nf1 & Nf2 & 0.941 \\
\hline
\end{tabular}

$\overline{\mathrm{NF}}=$ negative feature; $\mathrm{PE}=$ positive effect; $\mathrm{PI}=$ personal image; $\mathrm{SC}=$ service and cost.

Pearson's Product Moment Correlation Test. 
$(67 \%)$ of the total variance was deemed significant, the scree plot supported these results (Figure 2).

When factor analysis of the questionnaire was performed, subdimension factor loadings were found to range from 0.744 to 0.854 for "Positive Effect," 0.62 to 0.985 for "Personal Image and Appearance," and 0.903 to 0.913 for "Adverse Features"; the factor loading of "Service and Cost" was 0.983. As the factor loadings of all subdimensions were above 0.30 , hearing aid satisfaction can be assessed with all subscale items in the TSADL (if a factor loading value is higher than or equal to 0.3 , and there is a cluster of highly related substances within a factor, items are measured as a concept factor (Büyüköztürk, 2002). Although the scale retained the original four factors, as social structure and points of view of the Turkish community is different from others, questions 12 and 15 from the "Service and Cost" subdimension were found to be related to the "Positive Effect" subdimension and were evaluated within this subscale. Only question 14 remained in the "Service and Cost" subdimension, and thus this factor was renamed as the "Cost" subdimension. As it showed a high level of factor loading with the "Positive Effect" subdimension, question 11, an "Adverse Features" item, was excluded from the "Adverse Features" subdimension. To assess the test reproducibility, the questionnaire was applied to all patients 3 mo later; factor analysis yielded results consistent with the first application.

In the correlation analysis between items, the maximum correlations are expressed according to the factors. In the "Positive Effect" subdimension, correlations coefficients ranged from 0.506 to 0.903 . In the "Personal Image" subdimension, correlation coefficients ranged from 0.932 to 0.981 . In the "Adverse Features" subdimension, correlation coefficients ranged from 0.941 to 0.958 . When the correlation coefficients (which shows the strength and the direction of the association between items) were investigated, strong and linear relationship were found. The correlation between items are shown in Table 4.

The results obtained in the reliability, item-total correlation, and split-half tests are shown in Table 5.

Table 5. The Reliability, Item-Total Correlation, and Split-Half Test Results According to the Items

\begin{tabular}{|c|c|c|c|c|c|}
\hline \multirow[b]{2}{*}{$\begin{array}{l}\text { Scale } \\
\text { Subdimensions }\end{array}$} & \multirow[b]{2}{*}{ Items } & \multicolumn{3}{|c|}{ Overall } & \multirow{2}{*}{$\begin{array}{c}\text { Split-Half } \\
\text { Cronbach's Alpha } \\
\text { Part 1-Part } 2\end{array}$} \\
\hline & & $\begin{array}{l}\text { Cronbach's Alpha } \\
\text { When Item Deleted }\end{array}$ & $\begin{array}{l}\text { Total Item } \\
\text { Correlation }\end{array}$ & $\begin{array}{c}\text { Overall Cronbach's } \\
\text { Alpha }\end{array}$ & \\
\hline \multirow[t]{9}{*}{ Positive effect } & $\mathrm{Pe} 1$ & 0.914 & 0.709 & 0.920 & $0.880-0.887$ \\
\hline & $\mathrm{Pe} 2$ & 0.911 & 0.745 & & \\
\hline & Pe3 & 0.917 & 0.658 & & \\
\hline & $\mathrm{Pe} 4$ & 0.908 & 0.792 & & \\
\hline & Pe5 & 0.915 & 0.711 & & \\
\hline & Pe6 & 0.912 & 0.741 & & \\
\hline & Nf3 & 0.913 & 0.745 & & \\
\hline & Sc1 & 0.914 & 0.714 & & \\
\hline & Sc3 & 0.912 & 0.742 & & \\
\hline \multirow{3}{*}{$\begin{array}{l}\text { Personal image and } \\
\text { appearance }\end{array}$} & $\mathrm{Pi} 1$ & 0.960 & 0.966 & 0.974 & $0.989-0.944$ \\
\hline & $\mathrm{Pi} 2$ & 0.929 & 0.990 & & \\
\hline & $\mathrm{Pi} 3$ & 0.989 & 0.944 & & \\
\hline \multirow[t]{2}{*}{ Adverse features } & Nf1 & 0.974 & 0.941 & 0.963 & $0.952-0.975$ \\
\hline & $\mathrm{Nf2}$ & 0.982 & 0.941 & & \\
\hline Cost & Sc3 & - & - & - & - \\
\hline \multirow{15}{*}{ Overall } & Pe1 & 0.832 & 0.604 & 0.848 & $0.870-0.856$ \\
\hline & Nf1 & 0.839 & 0.680 & & \\
\hline & $\mathrm{Pe} 2$ & 0.833 & 0.596 & & \\
\hline & $\mathrm{Pi} 1$ & 0.849 & 0.710 & & \\
\hline & Pe3 & 0.838 & 0.680 & & \\
\hline & Pe4 & 0.828 & 0.668 & & \\
\hline & Nf2 & 0.839 & 0.690 & & \\
\hline & $\mathrm{Pi} 2$ & 0.847 & 0.375 & & \\
\hline & Pe5 & 0.836 & 0.531 & & \\
\hline & Pe6 & 0.831 & 0.653 & & \\
\hline & Nf3 & 0.833 & 0.651 & & \\
\hline & Sc1 & 0.837 & 0.549 & & \\
\hline & $\mathrm{Pi} 3$ & 0.844 & 0.687 & & \\
\hline & Sc2 & 0.866 & -0.070 & & \\
\hline & Sc3 & 0.832 & 0.640 & & \\
\hline
\end{tabular}

NF = negative feature; PE = positive effect; PI = personal image; SC = service and cost.

Reliability Test - Pearson's Product Moment Correlation Test. 


\section{Assessment of the Subscales}

The overall Cronbach's alpha value of the "Positive Effect" subdimension was 0.920, and the Cronbach's alpha values of the relevant items ranged from 0.911 to 0.991 . The internal consistencies of the items were sufficient. The correlation coefficients ranged from 0.658 to 0.792 . In the split-half reliability test analysis, the Cronbach's alpha values were calculated as 0.880 for part 1 and 0.887 for part 2 .

The overall Cronbach's alpha value of the "Personal Image" subdimension was 0.974 , and the Cronbach's alpha values of the relevant items ranged from 0.929 to 0.989 . The correlation coefficients ranged from 0.944 to 0.990 . In the split-half reliability test analysis, the Cronbach's alpha values were calculated as 0.889 for part 1 and 0.944 for part 2 .

The overall Cronbach's alpha value of the "Adverse Features" subdimension was 0.963 , and the Cronbach's alpha values of the relevant items ranged from 0.974 to 0.982 . The correlation coefficient was 0.941 . In the splithalf reliability test analysis, the Cronbach's alpha values were calculated as 0.952 for part 1 and 0.975 for part 2. When comparing the Cronbach's alpha coefficients of the original SADL subscales (Table 6) with the TSADL subscales, there was a high internal consistency of TSADL in the four subscales. The high Cronbach's alpha coefficients were similar to the previous SADL data for each subscale (Cox and Alexander, 2000).

Since the "Cost" subdimension included only one item, reliability analysis could not be performed.

When all items were evaluated together, the overall Cronbach's alpha value was 0.848 , and the Cronbach's alpha values for all items ranged from 0.828 to 0.866 .

Table 6. Test/Retest

\begin{tabular}{lccc}
\hline & N & $R$ & $P$ Value \\
\hline Pe1 \& Pe1 (3rd mo) & 160 & 0.917 & $<0.001$ \\
Nf1 \& Nf1 (3rd mo) & 160 & 0.977 & $<0.001$ \\
Pe2 \& Pe2 (3rd mo) & 160 & 0.997 & $<0.001$ \\
Pi1 \& Pi1 (3rd mo) & 160 & 0.983 & $<0.001$ \\
Pe3 \& Pe3 (3rd mo) & 160 & 0.966 & $<0.001$ \\
Pe4 \& Pe4 (3rd mo) & 160 & 0.983 & $<0.001$ \\
Nf2 \& Nf2 (3rd mo) & 160 & 0.972 & $<0.001$ \\
Pi2 \& Pi2 (3rd mo) & 160 & 0.870 & $<0.001$ \\
Pe5 \& Pe5 (3rd mo) & 160 & 0.967 & $<0.001$ \\
Pe6 \& Pe6 (3rd mo) & 160 & 0.976 & $<0.001$ \\
Nf3 \& Nf3 (3rd mo) & 160 & 0.991 & $<0.001$ \\
Sc1 \& Sc1 (3rd mo) & 160 & 0.976 & $<0.001$ \\
Pi3 \& Pi3 (3rd mo) & 160 & 0.795 & $<0.001$ \\
Sc2 \& Sc2 (3rd mo) & 160 & 0.982 & $<0.001$ \\
Sc3 \& Sc3 (3rd mo) & 160 & 0.960 & $<0.001$ \\
\hline NF = negative feature; PE = positive effect; Pl $=$ personal image; & \\
SC = service and cost. & \multicolumn{3}{l}{} \\
Pearson's Correlation Test - r: Correlation Coefficient. &
\end{tabular}

Internal consistencies were sufficient. Correlation coefficients ranged from 0.070 to 0.710 . The negatively valued item was question 14 . As it was factorized independently, the correlation coefficient was found to negative and weak. When split-half reliability analysis was conducted, the Cronbach's alpha values were calculated as 0.870 for part 1 and 0.856 for part 2 .

Test/retest results are shown in Table 6.

The second questionnaire implementation results, performed after $3 \mathrm{mo}$, were consistent with the results of the first implantation. Test/retest reliability was good $(r>0.7)$. The second questionnaire implementation, results performed after $3 \mathrm{mo}$, were consistent with the results of the first implantation. Test/retest was $\operatorname{good}(r>0.7)$.

CFA was performed to evaluate the extent to which the four-factor structure complied with the data obtained in our study. As one of the four factors obtained in the explanatory factor analysis consisted of only one question, the structural assessment was performed with the remaining 14 items and three factors. Although the consistency indices $\left(\chi^{2}=171,158 \mathrm{SD}=73, p<0.001\right)$ acquired via CFA revealed that the model was inconsistent $\left(\chi^{2} / \mathrm{SD}=171,158 / 73=2,345 \leq 3\right)$, it was concluded that the overall consistency of the model was acceptable. The CFA of the SADL questionnaire is shown in Figure 3.

When the other consistency indices were analyzed, the root mean square error of approximation was 0.072 , the normed fit index was 0.934 , the non-normed fit index was 0.951 , the goodness-of-fit index was 0.874 , and the adjusted goodness-of-fit index was 0.918 . The consistency indices of the SADL scale showed ideal consistency.

The SADL was adapted to the Turkish culture and calculation of satisfaction level was converted to percentage points. Accordingly, the following scoring instructions were constructed.

\section{TSADL Manual Scoring Instructions}

Instructions for manual scoring were evaluated as in the original scale. The results were converted to percentage values for enhanced comprehension and interpretation. Whereas Table 7 provides a value for each question, Table 8 provides the calculation template.

- The factors were calculated as a percentage according to the total scores proportional to the maximum total scores.

- In Item 11, if the patient checked the box describing good hearing on the phone without the use of a hearing aid, exclude this item from the "Adverse Features" subdimension calculation. The score will be the percentage score of Items 2 and 7.

- The overall score is a percentile expression of all items scores completed by the patient, provided that Item 11 is present as mentioned above. 


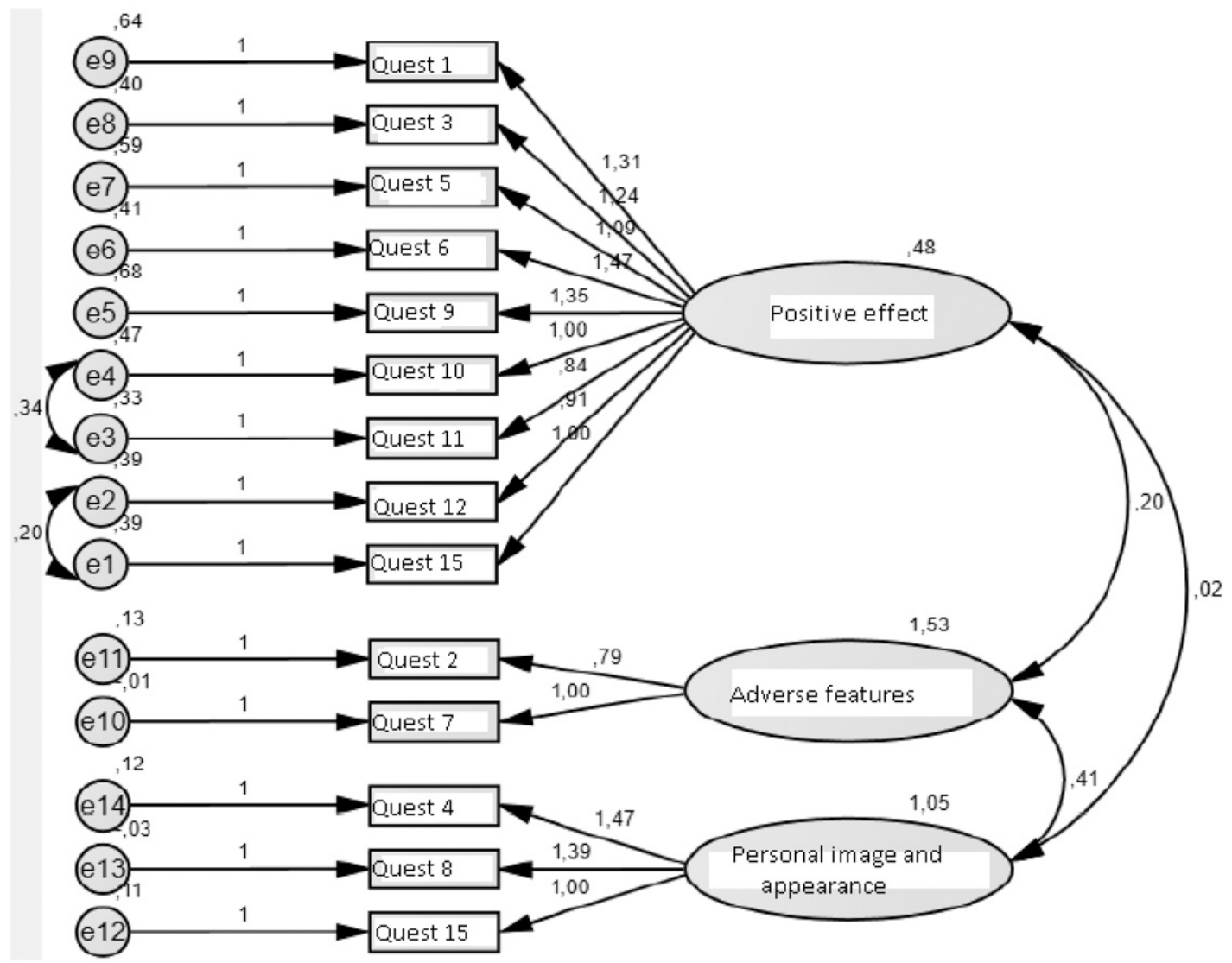

Figure 3. The CFA of the SADL scale.

\section{DISCUSSION}

A ssessing satisfaction with hearing aids is important for hearing aid adaptation in individuals with hearing loss.

Patient satisfaction is an entirely subjective concept, and it is not appropriate to connect satisfaction level with a single factor. Numerous questionnaires and evaluation forms have been developed to measure the benefit of hearing aids for patients (Vestergaard, 2006; Johnson et al, 2010). The SADL questionnaire is one of the most commonly used tests of hearing aid satisfaction (Hosford-Dunn and Halpern, 2001). The SADL questionnaire consists of 15 items grouped into four

Table 7. Assign a Value to Each Question in the Following Table

\begin{tabular}{lcc}
\hline Answer & Not an Inverse Item & Inverse Item \\
\hline A Not at all & 1 & 7 \\
B A little & 2 & 6 \\
C Somewhat & 3 & 5 \\
D Medium & 4 & 4 \\
E Considerably & 5 & 3 \\
F Greatly & 6 & 2 \\
G Tremendously & 7 & 1 \\
\hline
\end{tabular}

subscales: "Positive Effect," "Service and Cost," "Adverse Features," and "Personal Image." The most significant characteristic of the SADL questionnaire, which may have benefit in clinical applications, is the presence of a scale and availability of manual scoring of patient satisfaction. In this study, following factor analyses of the questions and subscales, all 15 questions were included in the scale. Factor analyses were applied to 15 questions and four subscales were determined, in agreement with the original scale.

Among the questionnaire subscales, "Positive Effect" covered psychological satisfaction, trial satisfaction, satisfaction with communication, and the improvement of natural sound quality. Cox and Alexander found a Cronbach's alpha value as 0.88 for this subscale (Cox and Alexander, 2000); in this study, the Cronbach's alpha value of the TSADL was found to be 0.920 . Thus, the positive effect subscale was found to be more reliable than the original study.

In the original SADL scoring, the cost component was excluded from the questionnaires of participants who did not make payment for their hearing aids, and the "Service and Cost" subscale score was determined by the two remaining items. However, in the TSADL implementation, as almost all hearing aid users had endured a certain cost for their hearing 
Table 8. The Calculation Template

\begin{tabular}{|c|c|c|c|c|}
\hline Subdimensions of the Scale & Items & Maximum Receivable Scores & Sample Scores & Calculation \\
\hline \multirow[t]{9}{*}{ Positive effect } & Pe1 & 7 & 6.00 & \multirow{10}{*}{$\frac{41}{63} * 100=65.07$} \\
\hline & Pe2 & 7 & 5.00 & \\
\hline & Pe3 & 7 & 4.00 & \\
\hline & Pe4 & 7 & 5.00 & \\
\hline & Pe5 & 7 & 6.00 & \\
\hline & Pe6 & 7 & 3.00 & \\
\hline & $\mathrm{Nf3}$ & 7 & 6.00 & \\
\hline & Sc1 & 7 & 1.00 & \\
\hline & Sc3 & 7 & 5.00 & \\
\hline Total & & 63 & 41.00 & \\
\hline \multirow[t]{3}{*}{ Personal image and appearance } & $\mathrm{Pi} 1^{*}$ & 7 & 5.00 & \multirow{3}{*}{$\frac{14}{21} * 100=66.7$} \\
\hline & $\mathrm{Pi} 2$ & 7 & 4.00 & \\
\hline & $\mathrm{Pi}^{*}$ & 7 & 5.00 & \\
\hline \multirow{3}{*}{ Adverse features } & & 21 & 14.00 & \\
\hline & $\mathrm{Nf}^{*}$ & 7 & 5.00 & $\underline{9} * 100=6$ \\
\hline & $\mathrm{Nf2*}$ & 7 & 4.00 & $\overline{14} \times 100=64.28$ \\
\hline \multirow[t]{2}{*}{ Total } & & 14 & 9.00 & \multirow{2}{*}{$\frac{5}{7} * 100=71.42$} \\
\hline & Sc2 & 7 & 5.00 & \\
\hline
\end{tabular}

$\overline{\mathrm{NF}}=$ negative feature; $\mathrm{PE}=$ positive effect; $\mathrm{PI}=$ personal image; $\mathrm{SC}=$ service and cost.

*Reverse questions.

aid (all of the participants in the questionnaire had made payment for the device), the subscale was organized with the inclusion of item 14 only. In the original study, the confidence level of the patient group in the hearing aid provider was determined to be quite high; however, whether the costs of the devices were appropriate or were not conclusive (Cox and Alexander, 2000). Similar results were obtained from the TSADL.

In this study, based on the outcome of factor analyses in the "Adverse Features" subscale, scores for items 2 and 7 were included in the subscale calculation. Although the Cronbach's alpha value was small in the original study, in the TSADL, it was calculated as 0.963 and, thus, the subscale was deemed to be quite reliable.

The "Personal Image" subscale associates personal image and device appearance with related fields. Cox and Alexander stated that satisfaction was important for hearing aid users; however, it was the least remarkable issue among other subjects such as benefit and service (Cox and Alexander, 1999). In the TSADL, this subscale was found to be quite reliable, with a Cronbach's alpha value of 0.974 , participants responded to this subscale with a high level of satisfaction.

In Australia, another country in which the validity and reliability of the SADL questionnaire was explored, reliability was found to be good (Uriarte et al, 2005). Australian users exhibited higher satisfaction in all SADL subscales, compared with users in the Unites States, and variables potentially affecting satisfaction level included perceived hearing difficulty in the absence of a hearing aid, amount of previous hearing aid experience, and the shape of the hearing aid (Uriarte et al, 2005).

In the Chinese translation and the reliability study of SADL, it was concluded that the questionnaire validity and reliability values were high, and the questionnaire was implementable (Fang et al, 2013). In addition, a study conducted by Meister et al in Germany, the reliability of the SADL questionnaire was found to be quite high (Meister et al, 2012).

As the result of our study, the TSADL questionnaire, which we found to be quite reliable, is a questionnaire with a manually graded scale, contrary to the other questionnaires. In the original study, to score each subscale, the average score of responses to scale items was calculated; in addition to the four subscale scores, replies were used to calculate a global score as an index of total satisfaction. In the Turkish implementation, for manual scoring, the seven-point Likert-type respondent scale was converted to percentile. The scoring and assessment instructions related to the global scale and the subscales were prepared in Turkish.

With the development of technology, major changes and improvements have started to take place in hearing aids. Together with new applications, the proper selection of hearing aids for patients, fitting applications, and follow-up of the benefits acquired have gained great importance. Technical problems, occurring after hearing aid selection, also affect its use. As some patients do not know what to do when they encounter very simple problems, they abandon the use of hearing aid. Therefore, for evaluation of hearing aid benefits, an inventory including the technical problems following hearing aid use should be used (Johnson et al, 2016). 
In this context, the SADL questionnaire is highly reliable, enabling evaluation of the benefit obtained together with subscales appropriate to the period of hearing aid usage. Moreover, because the questionnaire is brief and the indices are consistent, it is concluded that the current scale is implementable by investigators, and the consistency indices might be reanalyzed in different samples. Moreover, the simplicity and clarity of the questions, enabling immediate evaluation, provide a major advantage to clinicians.

\section{CONCLUSION}

A $\mathrm{s}$ the questionnaires reflect the experiences and satisfaction of hearing aid users during daily life, they can also be used to determine the application method that will be employed by the physician and in follow-up, along with the pure audiological measurements.

TSADL-TR has a total of 15 items, and approximately 10 min is sufficient for the completion and scoring of the questionnaire. When subscales are evaluated together, their significant areas concerning hearing aid users are incorporated.

Test/retest implementation of the SADL-TR questionnaire and subscales revealed no statistically significant difference. When all items were evaluated together to determine an optimum validity result, the overall Cronbach's alpha value was 0.848 (quite reliable). In item analysis, the Cronbach's alpha value ranged from 0.828 to 0.866 (quite reliable), and the internal consistencies of the items were determined as sufficient.

As the result of all performed analyses, the SADL-TR scale was concluded to be quite reliable for use in Turkish studies for quick evaluation of patient satisfaction, patient comparison, determination of normative satisfaction level, comparing various amplification types, and gathering administrative outcome data.

\section{REFERENCES}

Arslan E, Genovese E. (1996) Hearing aid systems in undeveloped, developed and industrialized countries. Scand Audiol Suppl 42: $35-39$.

Barcham LJ, Stephens SDG. (1980) The use of an open-ended problems questionnaire in auditory rehabilitation. $\mathrm{Br} J$ Audiol $14(2): 49-54$

Bille M, Parving A. (2003) Expectations about hearing aids: demographic and audiological predictors. Int J Audiol 42(8):481-488.

Büyüköztürk Ş. (2002) Factor analysis: basic concepts and using to development scale. Educational Administration in Theory and Practice 32:470-483.
Cox RM, Alexander GC. (2001) Validation of the SADL questionnaire. Ear Hear 22(2):151-160.

Cox RM, Alexander G-C. (2002) The international outcome inventory for hearing aids (IOI-HA): psychometric properties of the English version. Int $J$ Audiol 41(1):30-35.

Fang TY, Chang HJ, Wan TK, Wang PC, Chen YH. (2013) Validation of the Chinese version "satisfaction with amplification in daily life (SADL)" survey for hearing-aid users. Int J Audiol 52(7):478-484.

Gatehouse S. (1994) Components and determinants of hearing aid benefit. Ear Hear 15(1):30-49.

Hamurcu M, Şener BM, Ataş A, Atalay RB, Bora F, YİĞİT Ö. (2012) Evaluation of patients satisfaction with hearing aids. ENT-Forum 11(2):26-31.

Hosford-Dunn H. (2000) Hearing Aid User Attitudes. Textbook of Hearing Aid Amplification, 467.

Hosford-Dunn H, Halpern J. (2001) Clinical application of the SADL scale in private practice II: predictive validity of fitting variables. Satisfaction with amplification in daily life. $J$ Am Acad Audiol 12(1):15-36.

Johnson CE, Danhauer JL, Ellis BB, Jilla AM. (2016) Hearing aid benefit in patients with mild sensorineural hearing loss: a systematic review. J Am Acad Audiol 27(4):293-310.

Johnson JA, Cox RM, Alexander GC. (2010) Development of APHAB norms for WDRC hearing aids and comparisons with original norms. Ear Hear 31(1):47-55.

Kırkım G, Şerbetçioğlu B, Mutlu B. (2008) Assessment of patient satisfaction for hearing aids using the Turkish version of international outcome inventory for hearing aids. KBB ve BBC Dergisi 16:101-107.

Kumar S. (2001) WHO tackles hearing disabilities in developing world. Lancet 358(9277):219.

Lupsakko TA, Kautiainen HJ, Sulkava R. (2005) The non-use of hearing aids in people aged 75 years and over in the city of Kuopio in Finland. Eur Arch Otorhinolaryngol 262:165-169.

Matthews LJ, Lee FS, Mills JH, Schum DJ. (1990) Audiometric and subjective assessment of hearing handicap. Eur Arch Otorhinolaryngol 116:1325-1330.

Meister H, Grugel L, Meis M, Kiessling J. (2012) Use of self-assessment inventories in hearing-aid provision: German versions of ECHO and SADL. Int $J$ Audiol 51(2):135-142.

Stephens D. (2002) The International Outcome Inventory for Hearing Aids (IOI-HA) and its relationship to the Client-oriented Scale of Improvement (COSI). Int $J$ Audiol 41(1):42-47.

Uriarte M, Denzin L, Dunstan A, Sellars J, Hickson L. (2005) Measuring hearing aid outcomes using the Satisfaction with Amplification in Daily Life (SADL) questionnaire: Australian data. J Am Acad Audiol 16(6):383-402.

Vestergaard MD. (2006) Self-report outcome in new hearing-aid users: longitudinal trends and relationships between subjective measures of benefit and satisfaction. Int J Audiol 45(7):382-392.

Yearbook TS. (2004) Turkish Statistical Institute, Ankara. http://www.turkstat.gov.tr/yillik/yillik_ing.pdf. 